\title{
A study on finding influencing factors on diabetic retinopathy among diabetic patients using Multiple Regression approach
}

\author{
V. Senthilvel ${ }^{1}$, R. Radhakrishnan ${ }^{2}$, R. Sathiyamoorthi ${ }^{3}$, S. Sumathi ${ }^{4}$, \\ V. Jayanthi ${ }^{5}$ \\ ${ }^{1}$ Assistant Professor (Biostatistics), Pondicherry Institute of Medical Sciences, Ganapathychettikulam, \\ Puducherry (UT), South India. \\ ${ }^{2}$ Prof. in Statistics, P.S.G College of Arts and Science, Coimbatore, India. \\ ${ }^{3}$ Formerly HOD \& Prof., Dept. of Statistics, Annamalai University, Chidambaram, India. \\ ${ }^{4}$ Lecturer in Nursing $(O B G)$, Kasturba Gandhi College of Nursing, Pillaiyarkuppam, Puducherry. \\ ${ }^{5}$ Tutor in Medical Entomology, Pondicherry Institute of Medical Sciences, Puducherry.
}

\begin{abstract}
Background: Diabetic retinopathy (DR) is retinal disease associated with diabetes. DR is the leading cause of blindness among working aged adults around the world. High blood pressure is an established risk factor for the development of macular edema and is associated with the presence of PDR. Objective: To find the influence of factors in the prediction of DR by using multiple regression analysis approach and find out the thickness of the center of retina (macula). Methods: 200 diabetic retinopathy patients were selected through simple random sampling by using pre-designed and pre-tested questionnaire. Macular edema thickness is to be measured by Optical Coherence Tomography (OCT) in the unit of $\mu \mathrm{m}$ and to find other influencing factors age, gender, duration of diabetics, level of hyperglycemia $\left(H b A_{I c}\right), H D L$, triglycerides, family history, hypertension, LDL related to DR. Results: Out 200 patients, 133 (66.50\%) were male and $67(33.50 \%)$ were female. Mean age of the patients was $59.78 \pm 11.31$ years and range was $24-87$ years. The mean thickness of the center of the retina (macula) was $452.30 \pm 138.92 \mu \mathrm{m}$. In this paper, the influencing factors were indentified, gender and $H D L$ were had no influence over for developing DR. Conclusion: The influencing factors have been indentified and on the basis of which prediction of DR for a person is identified. By finding the influencing factors of DR and one can protect themselves from the development of DR.
\end{abstract}

Keywords: diabetic retinopathy, macular edema thickness, duration of diabetes, hypertension, multiple regression analysis approach.

\section{Introduction:}

Diabetic retinopathy is a condition occurring in persons with diabetes, which causes progressive damage to the retina, the light sensitive lining at the back of the eye [Figure.1]. It is a serious sight-threatening complication of diabetes. Persons with diabetic retinopathy can suffer significant vision loss [1]. Diabetic retinopathy is the result of damage caused by diabetes to the small blood vessels located in the retina. Blood vessels damaged from diabetic retinopathy can cause vision loss. Fluid can leak into the macula, the area of the retina which is responsible for clear central vision [1]. DR is the leading cause of blindness among working aged adults around the world [2]. DR, a complication of diabetes that occurs as a result of vascular changes in the retina, accounts for nearly five percent of the world's 37 million blind. In India with the epidemic increase in type 2 diabetes mellitus as reported by the World Health Organization (WHO) [3]. Despite the significance of this problem, and the rising prevalence of diabetes notably in emerging Asian countries like India and China [4,5], there are few precise contemporary estimates of the worldwide prevalence of DR, particularly severe vision-threatening stages of the disease, including proliferative DR (PDR) and diabetic macular edema (DME). High blood pressure is an established risk factor for the development of macular edema and is associated with the presence of PDR [Figure.2].

DR is one of the main causes of visual loss in individuals aged 20-64 years old [6] and is present in more than $77 \%$ of patients with DM type 2 who survive for over 20 years with the disease [7]. Many factors have been associated with the progression and severity of DR, such as DM duration [8,9], hypertension [10,11]. Vision loss due to diabetic retinopathy results from several mechanisms. Central vision may be impaired by macular edema or capillary non perfusion. Macular edema is often a complication of diabetic retinopathy, and is the most common form of vision loss for people with diabetes particularly if it is left untreated. In this paper, which are the influencing factors or the significant role in the occurrence of retinopathy in diabetic patients are to be identified and finding the thickness of the macula (center area of the retina) [Figure.1]. 


\section{Methods:}

A retrospective hospital based study was carried out in Aravind Eye Hospital, Thavalakuppam, Puducherry (UT) during January - February 2012. In this study, total sample size 200 was collected by using simple random sampling method. Data were collected by using pre-designed and pre-tested questionnaire. Patients with age 24 years and above were included in this study. The data set collected from 200 patients with DR. Optical coherence tomography (OCT) is a new medical diagnostic imaging technology which can perform micrometer resolution cross-sectional or tomographic imaging in biologic tissues [12]. The macula thickness was measured by OCT. In this study, we considered the influencing factors such as OCT value, age, gender, duration of diabetics, level of hyperglycemia $\left(\mathrm{HbA}_{1 \mathrm{c}}\right), \mathrm{HDL}$, triglycerides, family history, hypertension, $\mathrm{LDL}$. The influencing factors of DR are to be found. The data was entered in MS Excel 2007 and analyzed by using statistical software SPSS 16.0 version. ANOVA test was used for goodness of fit of the model, multiple regression analysis approach $[13,14]$ was used for the prediction of DR in an individual and p-value $<0.05$ was considered as statistically significant. In this study, the risk factors to be found out and how much they are influence in the development of DR have been computed.

For the Multiple Regression Analysis approach we take,

$\mathrm{Y}=\mathrm{OCT}$ value (in $\mu \mathrm{m}$ ) is considered as the dependent variable.

The following are the independent variables:

1. Age $\left(\mathrm{x}_{1}\right)$ in years

2. Gender $=1$, if male $\left(\mathrm{x}_{2}\right)$

$$
=0 \text {, if female }
$$

3. HbA1c (glycosylated haemoglobin) $\left(\mathrm{x}_{3}\right)$ in $\%$

4. Duration of Diabetics $\left(\mathrm{x}_{4}\right)$ in years

5. Triglyceride $\left(\mathrm{x}_{5}\right)$ in $\mathrm{mg} / \mathrm{dl}$

6. HDL $\left(\mathrm{x}_{10}\right)$ in $\mathrm{mg} / \mathrm{dl}$

7. Family History $=1$ if Retinopathy was indentified with patients $\left(\mathrm{x}_{7}\right)$

$$
=0 \text { if not }
$$

8. Hypertension $=1$ if a person had high blood pressure $\left(\mathrm{x}_{8}\right)$

9. LDL $\left(\mathrm{x}_{9}\right)$ in $\mathrm{mg} / \mathrm{dl}$

$$
=0 \text { if not }
$$

\section{Results:}

Among 200 patients, $133(66.50 \%)$ were male and $67(33.50 \%)$ were female. Mean age of the patients was $49.38 \pm 11.31$ (Mean \pm S.D) years and range was $24-87$ years. The mean thickness of the center of the retina (macula) was $452.30 \pm 138.92 \mu \mathrm{m}$. From the multiple regression analysis the following results have been obtained: ANOVA test for goodness of fit shows that the regression F-value is 53.827 with a corresponding pvalue $=0.000(\mathrm{p}<0.001)$. ie., it was highly statistically significant, and this proved that the model is a good fit for prediction of the development of DR. In the analysis, the R-square value was 0.718 and we can predict the selected variables for this multiple regression model are very much influencing in the development of DR. The influencing variables, their regression co-efficients (B) and their level of significance are shown in [Table 1]. After finding the regression co-efficient, we can form the Multiple Regression Equation as follows,

$$
\mathbf{Y}=\mathbf{B}_{0}+\mathbf{B}_{1} \mathbf{x}_{1}+\mathbf{B}_{3} \mathbf{x}_{3}+\ldots \ldots \ldots+\mathbf{B}_{9} \mathbf{B}_{9}
$$

Using this regression equation it is possible to predict the expected value of

Example:

For a given person the values of the different independent variables are:

From table (1),

$$
\begin{aligned}
& \beta_{0}=148.840, x_{1}=1.035, x_{3}=1.387, x_{4}=13.631, x_{5}=0.787, x_{7}=1.750, x_{8}=33.831 \text {, } \\
& \mathrm{x}_{9}=1.027 \\
& \mathbf{Y}=\mathbf{B}_{0}+\mathbf{B}_{1} \mathbf{x}_{1}+\mathbf{B}_{3} \mathbf{x}_{3}+\mathbf{B}_{4} \mathbf{x}_{4}+\mathbf{B}_{5} \mathbf{x}_{5}+\mathbf{B}_{7} \mathbf{x}_{7}+\mathbf{B}_{8} \mathbf{B}_{8}+\mathbf{B}_{9} \mathbf{B}_{9} \\
& \mathrm{Y}=148.840+1.035(75)+1.387(11.3)+13.631(10)+0.787(75)+1.750(1) \\
& +33.831(1)+1.027(54) \\
& \mathrm{Y}=148.840+77.625+15.673+136.31+59.025+1.750+33.831+55.458 \\
& \mathrm{Y}=528.51 \mu \mathrm{m}
\end{aligned}
$$

In above the example, for an individual, we have to find the thickness of macular edema was $528.51 \mu \mathrm{m}$.

\section{Discussion:}

Diabetic Retinopathy (DR) is one of the dreaded complications and DM is a basic and leading factor which contributes to acquire blindness. The concept of DR has been investigated by several authors. The association between LDL cholesterol and severity of DR has been studied by T.L. Dornan et al [15]. In this 
study, the variables such as optical coherence tomography (OCT) value, age, duration of diabetics, level of hyperglycemia $\left(\mathrm{HbA}_{1 \mathrm{c}}\right)$, triglycerides, family history, hypertension, LDL play a significant $(\mathrm{p}<0.05)$ role except gender and HDL was not significant ( $p>0.05$ ) in the occurrence of DR. The propensity to develop DR is lower in south India when compared to the other populations [16]. Observations indicate an association of serum lipid level (LDL) with lipid in the retina (hard exudates) and visual loss. Thus, serum lipid level may be important in the management of DR [11].

Most of patients $67(33.50 \%)$ were affected by DR in the age-group of $51-60$ years and followed by $61(30.50 \%)$ were in the age-group of 61-70 years. In this study, the mean duration of diabetes [11] of the diabetic patient was calculated as $15.32 \pm 7.83$ yrs (mean $\pm \mathrm{SD}$ ). Similar type of results has been shown that nearly 75 per cent of type II diabetes will develop DR after 15 years duration of diabetes as shown in the epidemiological study [17]. Hence, the duration of DM is significant with the progression of macular edema. Some DR patients may develop vision loss from DME. Clinically significant macular edema (CSME) occurs if there is thickening of the retina involving the center of the retina (macula) or the area within $500 \mu \mathrm{m}$ of it, if there are hard exudates at or within $500 \mu \mathrm{m}$ of the center of the retina with thickening of the adjacent retina, or if there is a zone of retinal thickening one disk area or larger in size, any part of which is within one disk diameter of the center of the retina [18]. This definition of CSME generally refers to the threshold level at which laser photocoagulation is carried out. However, it is important to appreciate that the majority of visual loss occurs when macular edema involves the center.

\section{Conclusion:}

Awareness created with the DR patients through Information Education and Communication (IEC) activity then we will reduce the vision-threatening complaints as well as the incidence of DR in India. As per the ophthalmologist advice, one can test their eyes and other finding of the DR in time, and then they control themselves in the particular normal range and to protect them from the vision-threatening disease DR. By finding the influencing factors of developing DR, one can protect them from DR or it has to be reduced remarkably.

\section{Acknowledgements}

The authors are thankful to Dr. Venkatesh, Chief Medical Officer, Aravind Eye Hospital, Thavalakuppam, Puducherry (UT), South India for his help in obtaining the data for the study and also the guidelines provided for this work. The authors also wish to thanks to Mr. Sugumar, Optometric technician in the Retina centre, Aravind Eye Hospital, Puducherry for his help in data collection for this study.

\section{References:}

[1] Diabetic Retinopathy: available on http://www.aoa.org/diabetic-retinopathy.xml [Last accessed on 23th February, 2012]

[2] Klein BE. Overview of epidemiologic studies of diabetic retinopathy. Ophthalmic Epidemiol 2007;14:p179-183

[3] Wild S, Roglic G, Green A, Sicree R, King H. Global prevalence of diabetes, estimates for the year 2000 and projections for 2030. Diabetes Care 2004; $27:$ p1047-53.

[4] Shaw JE, Sicree RA, Zimmet PZ. Global estimates of the prevalence of diabetes for 2010 and 2030. Diabetes Res Clin Pract 2010;87: p4-14.

[5] Yang W, Lu J, Weng J, et al.; China National Diabetes and Metabolic Disorders Study Group Prevalence of diabetes among men and women in China. N Engl J Med 2010;362:p1090-110.

[6] Centers for Disease Control and Prevention (CDC): Blindness caused by diabetes- Massachusetts, 1987-1994. MMWR Morb Mortal Wkly Rep1996, 45:p937-941.

[7] Wild S, Roglic G, Green A, Sicree R, King H: Global prevalence of diabetes: Estimates for the year 2000 and projections for 2030. Diabetes Care2004, 27:p1047-1053.

[8] Bamashmus MA, Gunaid AA, Khandekar RB: Diabetic retinopathy, visual impairment and ocular status among patients with diabetes mellitus in Yemen: a hospital-based study. Indian J Ophthalmol 2009, 57:p293-298.

[9] Rani PK, Raman R, Chandrakantan A, Pal SS, Perumal GM, Sharma T: Risk factors for diabetic retinopathy in self-reported rural population with diabetes. J Postgrad Med 2009, 55:p92-96.

[10] Wang S, Xu L, Jonas JB, Wong TY, Cui T, Li Y, Wang YX, You QS, Yang H, Sun C: Major Eye Diseases and Risk Factors Associated with Systemic Hypertension in an Adult Chinese Population The Beijing Eye Study. Ophthalmology 2009, 116:p2373-2380.

[11] American Diabetes Association: Diabetic Retinopathy - Diabetes Care January 2002 Vol.25 no. suppl: s90 - s93

[12] Chauhan DS, Marshall J. The interpretation of optical coherence tomography images of the retina. Invest Ophthalmol Vis Sci. $1999 ; 40: 2332-2342$.

[13] http://www.palgrave.com/pdfs/0333734718.pdf [ Last accessed on 24th February, 2012]

[14] http://www.unesco.org/webworld/idams/advguide/Chapt5_2.htm [Last accessed on 24th February, 2012]

[15] T.L.Dornan, R.D. Carter, A.J. Bron, R.C. Turner and J. I. Mann. Low density lipoprotein cholesterol: An association with the severity of diabetic retinopathy: Diabetologia 1982; 22: p167 - 170.

[16] M. Rema \& R. Pradeepa - Diabetic Retinopathy: An Indian perspective: Indian J Med Res 125, March 2007, p 297-310.

[17] Klein R, Klein BEK, Moss SE, Davis MD, DeMets DL.(1984) The Wisconsin epidemiologic study of diabetic retinopathy III. Prevalence and risk of diabetic retinopathy when age at diagnosis is 30 or more years. Arch Ophthalmol; 1984, 102: p527-32.

[18] Early Treatment Diabetic Retinopathy Study Research Group: Photocoagulation for diabetic macular edema: Early Treatment Diabetic Retinopathy Study Report No. 1. Arch Ophthalmol 1985, 103: p1796-1806, 1985 
A study on finding influencing factors on diabetic retinopathy among diabetic patients using Multiple

VII. FIGURES AND TABLES

Table: 1 Influencing variables, their regression co-efficient $(B)$ and their level of significance

\begin{tabular}{|c|c|c|c|c|c|c|c|c|}
\hline \multirow[b]{2}{*}{ Model } & \multicolumn{2}{|c|}{$\begin{array}{c}\text { Unstandardized } \\
\text { Coefficients }\end{array}$} & \multirow{2}{*}{$\begin{array}{c}\begin{array}{c}\text { Standardized } \\
\text { Coefficients }\end{array} \\
\text { Beta } \\
\end{array}$} & \multirow[b]{2}{*}{ t-value } & \multirow[b]{2}{*}{ Sig. } & \multicolumn{2}{|c|}{$95 \%$ C.I for B } & \multirow[b]{2}{*}{ Result } \\
\hline & B & $\begin{array}{l}\text { Std. } \\
\text { Error }\end{array}$ & & & & Lower Bound & Upper Bound & \\
\hline Constant & 148.840 & 59.646 & & 2.495 & 0.013 & 31.187 & 266.493 & Sig, \\
\hline Age & 1.035 & 0.514 & 0.084 & 2.013 & 0.046 & 0.021 & 2.049 & Sig. \\
\hline Gender & -6.651 & 11.474 & -0.023 & -0.580 & 0.563 & -29.284 & 15.981 & N. Sig. \\
\hline $\mathrm{HbA}_{1 \mathrm{c}}$ & 1.387 & 2.479 & 0.023 & 0.560 & 0.036 & -3.503 & 6.277 & Sig. \\
\hline Duration of diabetics & 13.631 & 0.786 & 0.768 & 17.339 & 0.000 & 12.080 & 15.181 & H. Sig. \\
\hline Triglycerides & 0.787 & 0.412 & 0.077 & 1.911 & 0.047 & -0.025 & 1.599 & Sig. \\
\hline HDL & 0.139 & 0.463 & 0.012 & 0.299 & 0.765 & -0.776 & 1.053 & N. Sig. \\
\hline Family history & 1.750 & 10.888 & 0.006 & 0.161 & 0.031 & -19.727 & 23.226 & Sig. \\
\hline Hypertension & 33.831 & 13.292 & 0.100 & 2.545 & 0.012 & 7.612 & 60.051 & Sig. \\
\hline LDL & 1.027 & 0.504 & 0.087 & 2.037 & 0.043 & 0.033 & 2.022 & Sig. \\
\hline
\end{tabular}

Sig. - Significant $(\mathrm{p}<0.05)$ N. Sig. - Not Significant $(\mathrm{p}>0.05)$ H. Sig. - Highly Significant $(\mathrm{p}<0.001)$

C.I - Confidence Interval

Figure. 1 Medical image of the human eye

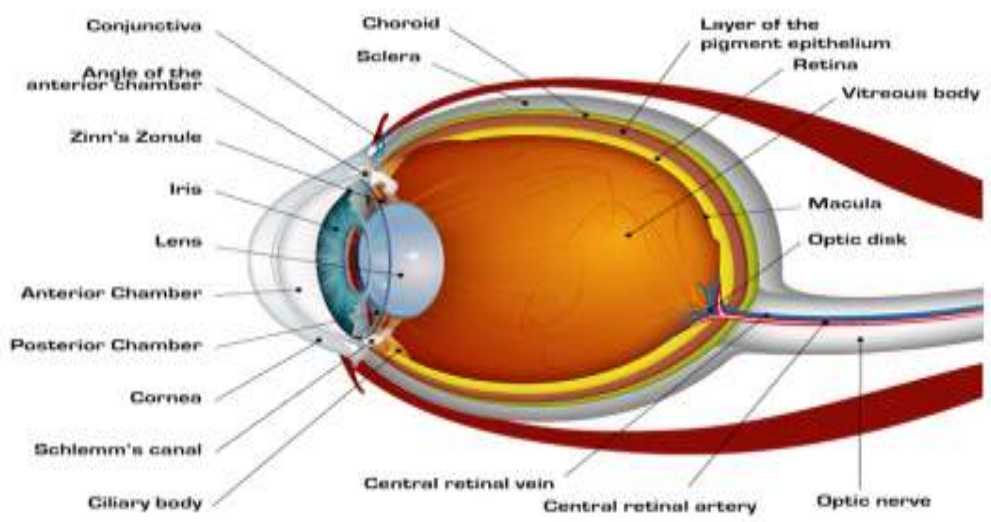

Figure.2 Proliferative diabetic retinopathy (PDR)

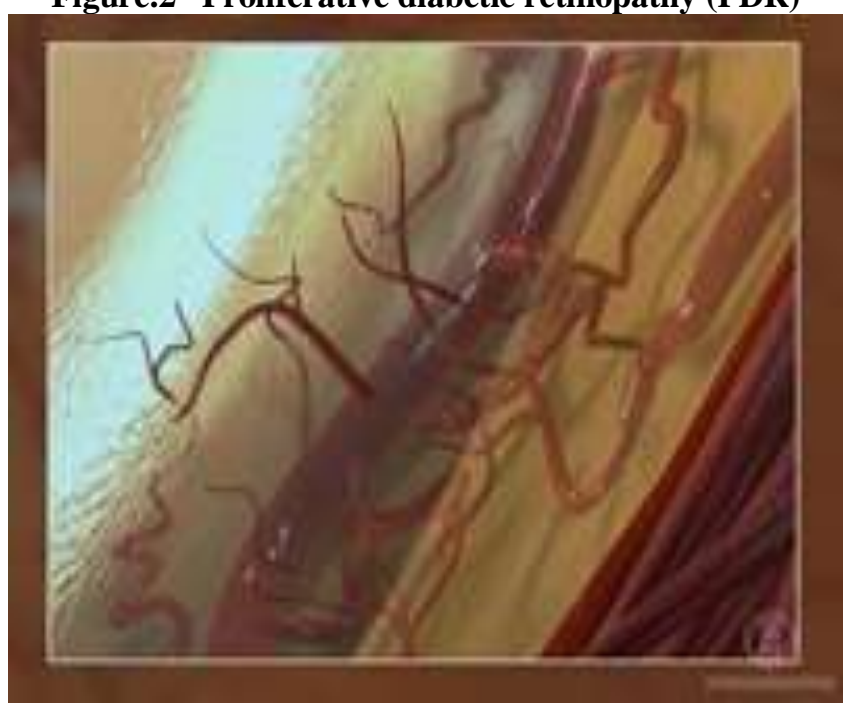

